\title{
IDENTIFICAÇÃO E MAPEAMENTO DE ÁREAS SUSCETÍVEIS A INUNDAÇÃO NA BACIA DO ARICANDUVA - SP UTILIZANDO O ALGORITMO DESCRITOR DE TERRENO HAND
}

\author{
Camila Galindo Dantas $^{(\mathrm{a})}$, Katia Canil ${ }^{(\mathrm{b})}$ \\ (a) Mestranda em Ciência e Tecnologia Ambiental, Universidade Federal do ABC,camila.galindodantas@gmail.com \\ (b) Geógrafa, professora do Centro de Engenharia, Modelagem e Ciências Sociais Aplicadas e dos programas de Pós \\ Graduação em Planejamento e Gestão do Território e em Ciência e Tecnologia Ambiental , Universidade Federal do \\ ABC, katiaccanil@gmail.com
}

\section{Eixo: GEOGRAFIA FÍSICA E DESASTRES NATURAIS}

\begin{abstract}
Resumo
Desastres naturais como inundações demandam mapeamentos e estudos diagnósticos do meio físico que visem oferecer aporte a ações de mitigação e gestão das áreas afetadas. No presente trabalho foi aplicado o modelo HAND (Height Above the Nearest Drainage) para a região da Bacia do Aricanduva, situada no município de São Paulo, SP, que é frequentemente atingida por inundações. Foi possível observar que o intervalo definido pelas alturas de inundação de 1-2 metros representa de forma satisfatórias as áreas suscetíveis a processos de acúmulo de água na área de estudo, caracterizando o modelo como uma importante ferramenta para estudos diagnósticos de detecção de áreas úmidas, buscando embasar medidas mitigatórias e propostas de gestão das áreas mais severamente afetadas por inundações.
\end{abstract}

Palavras chave: Bacia do Aricanduva, inundações, modelo HAND, suscetibilidade.

\section{Introdução}

Desastres naturais como inundações são reconhecidamente associados às características do meio físico em consonância com os processos antrópicos envolvidos. A prevenção e mitigação desses desastres vem sendo possível a partir de técnicas de mapeamentos e modelos que visam conhecer o território e oferecer diagnósticos, buscando avaliar a suscetibilidade e os riscos de uma determinada área frente à ocorrência de um desastre (KOBYIAMA et al., 2006).

Torna-se então imprescindível, no contexto da temática de prevenção de desastres, identificar aspectos do meio físico que corroboram para a ocorrência de determinados eventos, como as inundações. A relação entre as características do meio físico com o modo de ocupação do território podem gerar condições para que esses processos ocorram, demandando estudos e mapeamentos que visem compreender o problema e auxiliar em sua prevenção e mitigação. 
A bacia do rio Aricanduva, SP/SPapresenta significativo histórico de intensas e persistentes inundações, as quais geram diversos impactos socioeconômicos, como danos a equipamentos e edificações públicas e privadas, dificuldades sobre a circulação de pessoas e veículos e ameaça às vidas humanas.

Sinaliza-se, então, a necessidade de estudos diagnósticos, indicação de medidas de mitigação e elaboração de propostas de gestão para esta área, propondo o manejo e o controle do cenário descrito, buscando sobretudo a mitigação dos impactos sobre as comunidades continuamente atingidas.

.O modelo HAND (HEIGHT Above the Nearest Drainage) emerge como uma eficiente ferramenta de modelagem de terreno, onde é possível obter um mapeamento das áreas suscetíveis ao acúmulo de água, assim, definir graus de suscetibiliade, limites e/ou trechos afetados para então propor medidas de prevenção e controle para tornar mais resiliente as áreas atingidas.

\section{Caracterização da área de estudo}

A bacia do rio Aricanduva é uma das maiores e mais importantes da Região Metropolitana de São Paulo. Trata-se de uma sub-bacia do Alto Tietê e possui uma área total de $100 \mathrm{~km}^{2}$, aproximadamente, tendo suas nascentesno próprio município de São Paulo. 


\section{OS DESAFIOS DA GEOGRAFIA FÍSICA NA FRONTEIRA DO CONHECIMENTO Instituto de Geociências - Unicamp \\ Campinas - SP \\ 28 de Junho à 02 de Julho de 2017}

\section{Localização Bacia do Aricanduva}
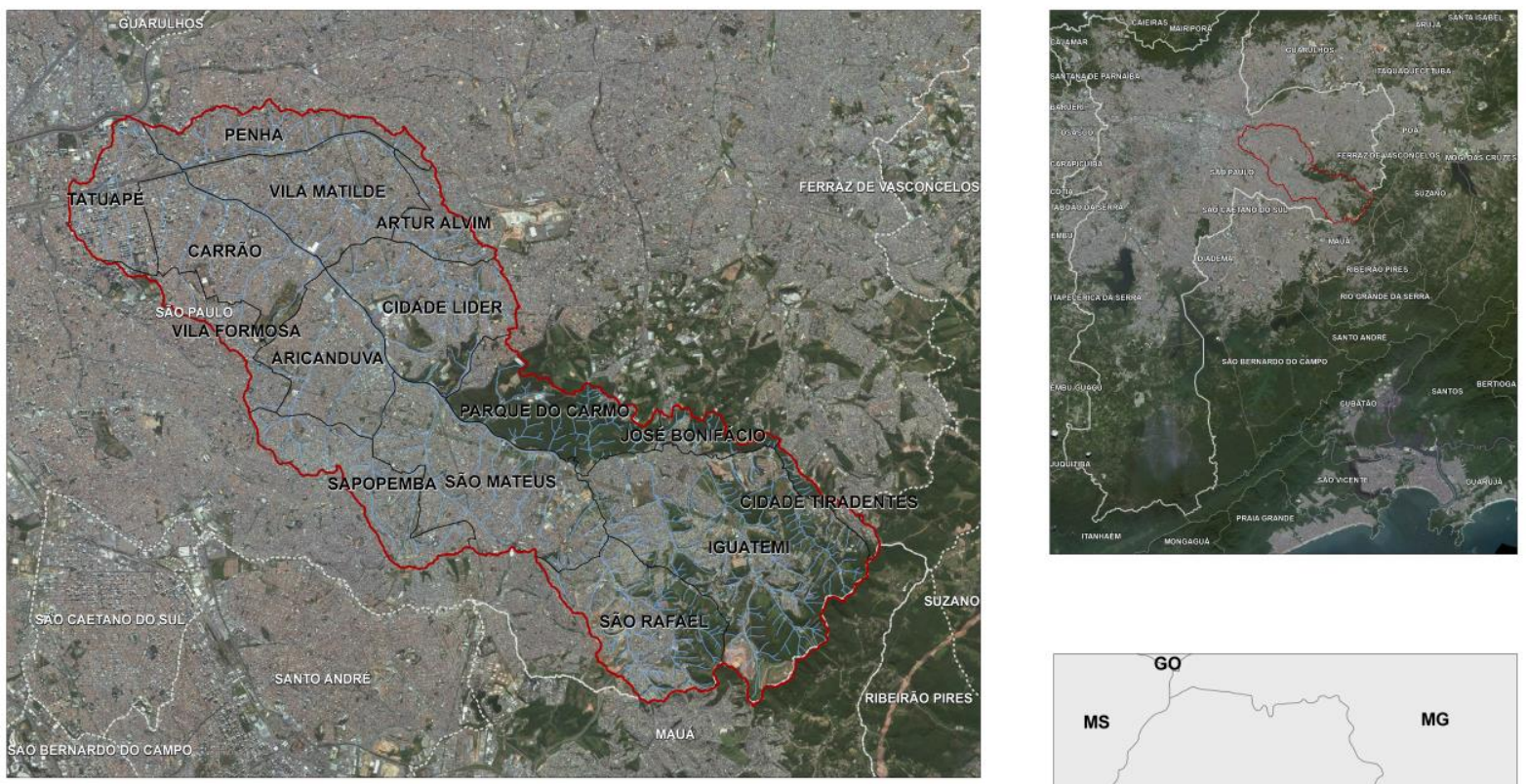

LEGENDA
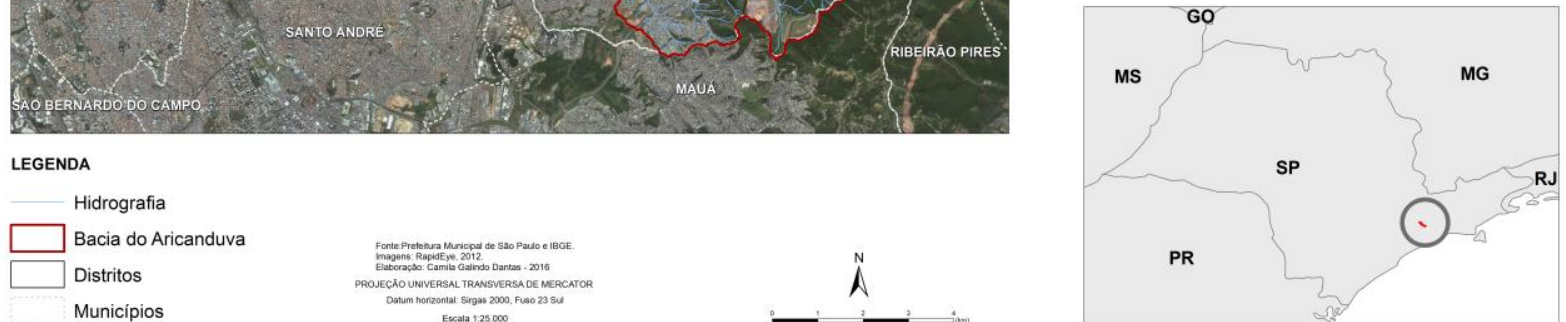

Figura 1 - Mapa da localização da bacia do Aricanduva e dos distritos de São Paulo. Fonte: Organizado por Camila Galindo Dantas. Imagens: RapidEye (2012).

Em relação aos aspectos físicos da bacia, o relevo é caracterizado por altas declividades nas porções de cabeceiras e extensas áreas de planície de inundação no baixo e médio curso do rio Aricanduva, associados aos aspectos climático-hidrológicos, apresentando eventos extremos de chuvas no verão, indicam uma alta suscetibilidade para a ocorrência de inundações (DAEE, 1999).

Considerando as características naturais e o cenário de expansão urbana, onde as áreas periféricas tendem ao aumento crescente da população,observa-se a tendência de um processo de adensamento do uso e ocupação do solo (em grande parte da bacia), gerando alta impermeabilização do solo, o que dificulta o escoamento das águas pluviais (CANHOLI, 2014).

\section{Processos de inundação, Risco e Desastres Naturais}

As inundações caracterizam-se como um evento excepcional e ocorrem quando o rio transborda de forma inesperada, sobretudo quando tem seu ambiente natural modificado, o que ocorre nas áreas urbanas, como é o caso da área de estudo (BOTELHO, 2011). 


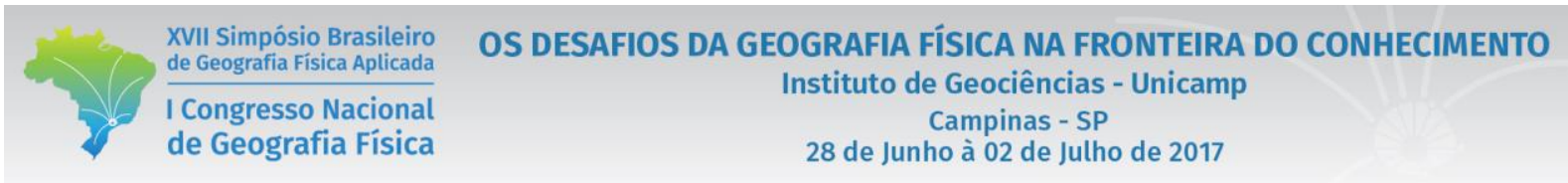

Estas diferenciam-se das enchentes, que se tratam do transbordamento natural do rio, ocorrendo de forma mais branda. De acordo com Carvalho et al. (2007 apud REIS, 2011, p.90) a enchente é “[...] um processo natural que ocorre nos cursos de água. Consiste na elevação temporária do nível d'água em um canal de drenagem (rio, córrego, riacho, arroio, ribeirão) devido ao aumento da vazão ou descarga".
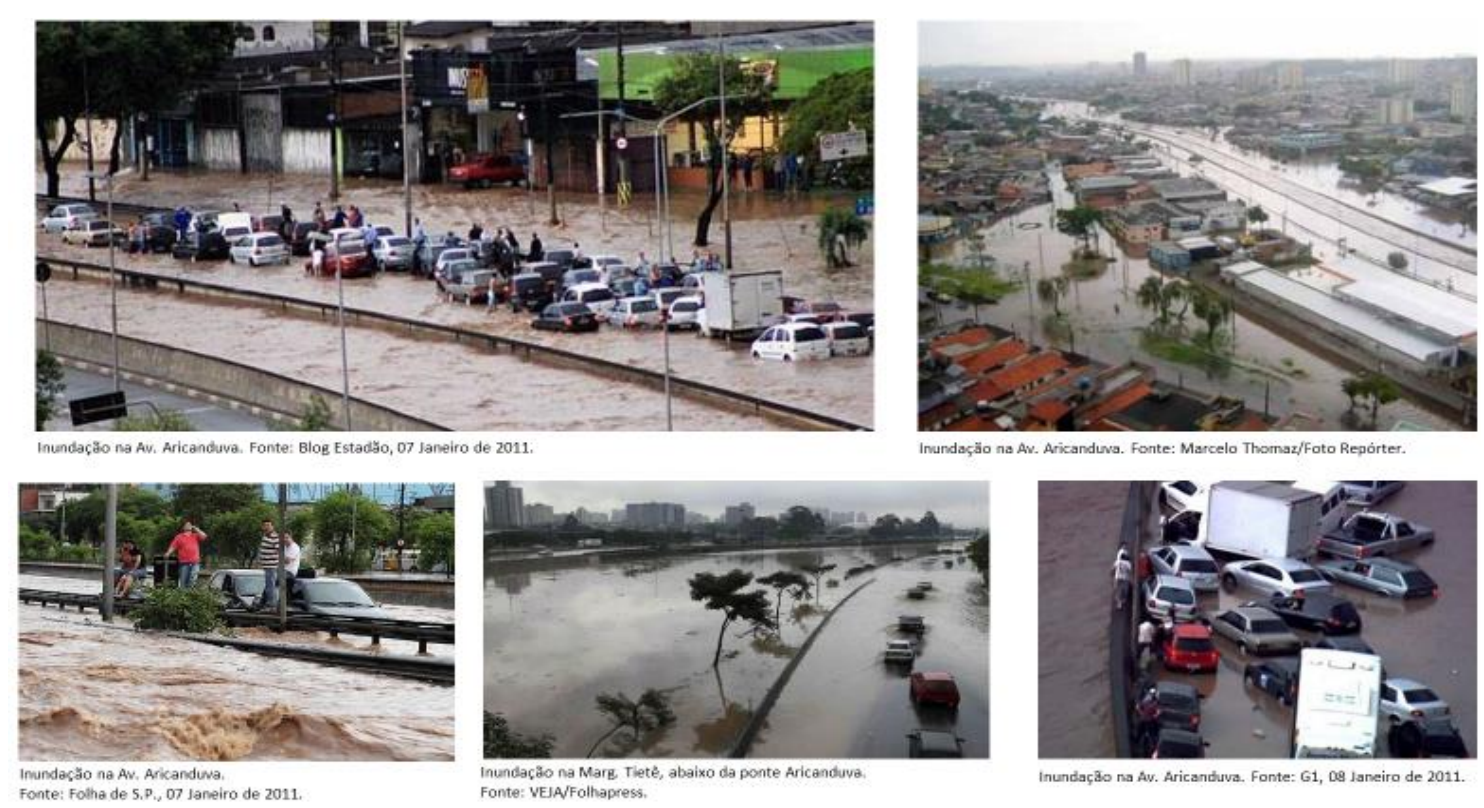

Figura 2 - Registros fotográficos de episódios de inundação na bacia do rio Aricanduva. Fonte: Organizado por Camila Galindo Dantas.

Alguns conceitos de geomorfologia fluvial tornam mais claro de que forma ocorrem as enchentes nos rios. A partir da diferenciação feita por Cunha (2012, p. 212) dos tipos de leitos fluviais, tem-se que:

O leito fluvial corresponde ao espaço ocupado pelo escoamento das águas. De acordo com a frequência das descargas e a consequente topografia dos canais fluviais, os leitos podem assumir a seguinte classificação (Tricart, 1966): leito menor, de vazante, maior e excepcional.

O leito menor corresponde à parte do canal ocupada pelas águas [...]. Esse tipo de leito é delimitado por margens bem definidas. $\mathrm{O}$ leito de vazante equivale à parte do canal ocupada durante o escoamento das águas de vazante [...]. O leito maior [...] é ocupado pelas águas do rio regularmente e, pelo menos uma vez ao ano, durante as cheias. O leito maior excepcional é ocupado durante as grandes cheias, no decorrer das enchentes.

As consequências das inundações são mais graves, ocorrendo em ambientes alterados por atividades antrópicas, conforme diz Botelho (1985 apud CUSTÓDIO, 2002, p. 8): “[...] rios e riachos sempre têm 


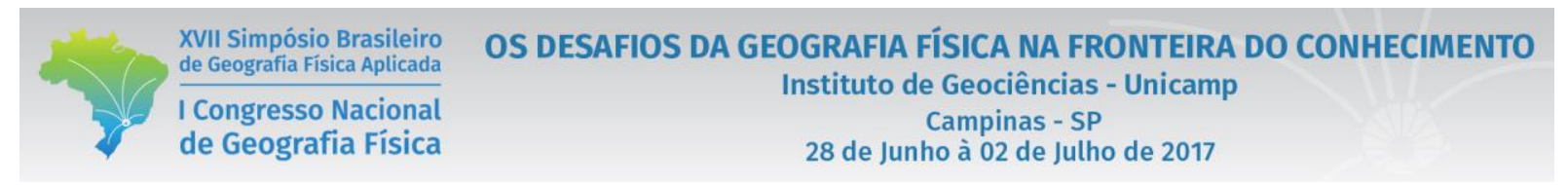

enchentes periódicas. Só ocorrem inundações quando a área natural de passagem da enchente de um rio foi ocupada por uma avenida (avenida de fundo de vale) ou por prédios".

Tal colocação reforça a ideia de que o fator social, representado na ocupação humana em área indevidas, como planícies fluviais, tem influência direta na ocorrência das inundações.

Portanto, será utilizado o termo "inundação" (Figura 3) no estudo, conforme Figura 3 consideramos os efeitos da urbanização da área e do uso e ocupação do solo.

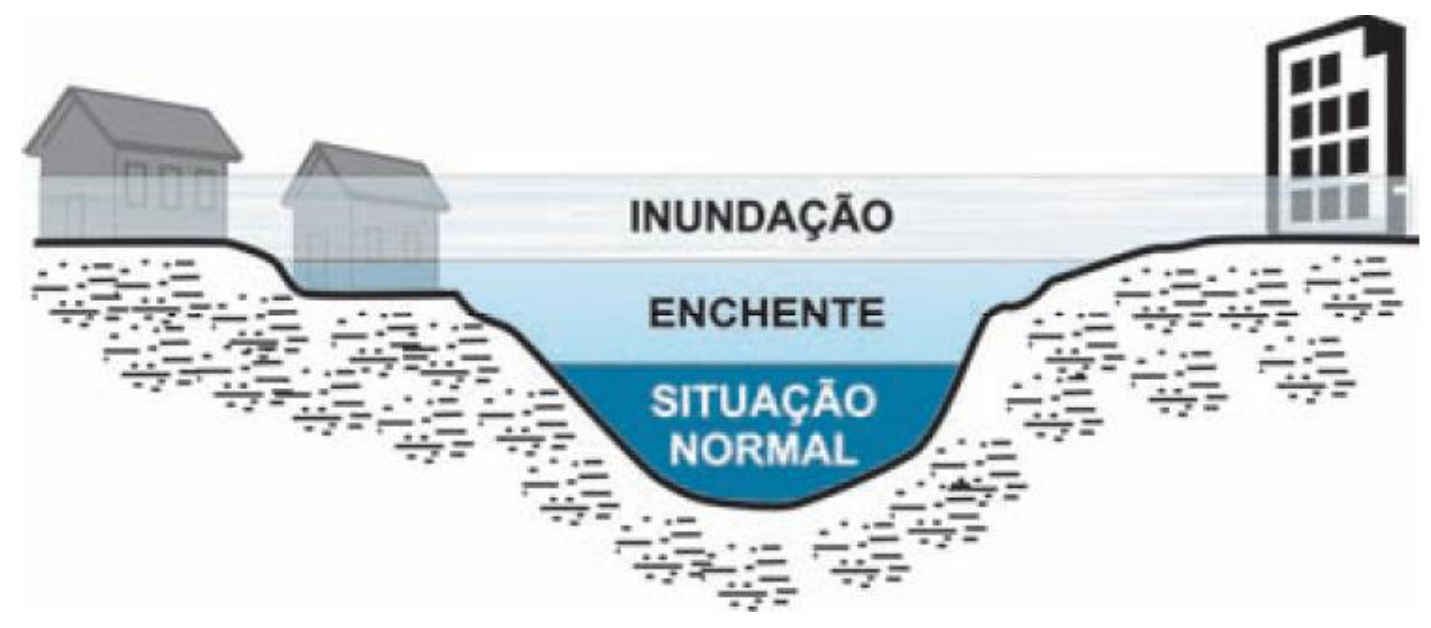

Figura 3 - Ilustração da situação de inundação. Fonte: Ministério das Cidades/IPT (2007).

Os episódios de inundação, sobretudo os mais severos, podem ser avaliados como um risco à população por conta da ameaça à vida e a propriedades.

Risco corresponde a uma medida da ameaça e das consequências (financeiras, bens, vidas) que esta poderá causar num dado intervalo de tempo. A estimativa de risco integra as análises de perigo/perigosidade e de consequências, incluindo nesta última a vulnerabilidade dos elementos expostos (CERRI; AMARAL, 1998; CARVALHO; GALVÃO, 2006; CARVALHO; MACEDO; OGURA, 2007; FELL et al., 2008; JULIÃO et al., 2009; MACEDO; BRESSANI, 2013 apud IPT (2014)).

O conceito de risco está relacionado aos de suscetibilidade e de vulnerabilidade, pois quanto maior esses dois últimos, mais o risco, ou seja, a chance de ocorrer um desastre natural.

O termo suscetibilidade indica a probabilidade de ocorrência de um desastre natural determinado. De acordo com IPT (2014, p.3), é a "propensão ao desenvolvimento de um fenômeno ou processo em uma dada área". 
Associado ao termo suscetibilidade, está o conceito de vulnerabilidade, que revela a "consequência" dos eventos no ambiente frente à ocorrência de processos como as inundações, ou seja, a vulnerabilidade aponta os possíveis danos às pessoas e equipamentos atingidos.

A análise e o mapeamento do relevo de planícies propiciam a compreensão da aptidão natural das áreas caracterizadas por essa forma, revelando a tendência para que haja inundações na área de estudo, compondo os conceitos de suscetibilidade, vulnerabilidade e risco.

Esses fenômenos podem estar ligados à dinâmica hidrológica de bacias hidrográficas associada ao comportamento de rios, onde suas planícies sofrem com os "desastres naturais" das inundações.

Ao apresentar um índice de suscetibilidade e vulnerabilidade elevados, as áreas baixas da bacia do Aricanduva configuram-se como "áreas de risco".

A questão da resiliência emerge como um importante paradigma norteador de estudos de gestão de área de risco pois consiste basicamente, em preparar a população e o ambiente para enfrentar situações de risco como inundações ou deslizamentos (ONU, 2012).

Conforme verifica-se na equação abaixo (Figura 4), a resiliência, ou a forma com que a população vulnerável é preparada para lidar com ameaças, reduz o risco do desastre.

\section{Ameaça x Vulnerabilidade x Exposição \\ Resiliência ou Capacidades de Enfrentamento

$$
=\text { Risco de Desastre }
$$

Figura 4 - Equação de risco de desastre. Fonte: ONU, UNISDR (2012).

As práticas resilientes são diversas e podem abarcar desde o diagnóstico e mapeamento do ambiente, indicando os graus de suscetibilidade, regiões de risco mais elevado, até a indicação de medidas de intervenção no meio, estruturais e não estruturais.

Entre as práticas de maior sucesso estão a criação de modelos de alerta e sistemas de previsão e melhoria da infraestrutura urbana.

\section{Modelo HAND (Height Above the Nearest Drainage)}

O modelo HAND foi a ferramenta utilizada com o intuito de identificar as áreas propícias ao acúmulo de água, ou seja, um método capaz de analisar a suscetibilidade natural do terreno à ocorrência de inundações. 
O modelo HAND (Height Above the Nearest Drainage - Altura Acima da Drenagem Mais Próxima) foi desenvolvido por pesquisadores do Instituto Nacional de Pesquisas Espaciais (INPE) em parceria com o Instituto Nacional de Pesquisa da Amazônia (INPA) e trata-se de um algoritmo que relaciona as características topográficas do terreno com as hidrológicas (RENNÓ et al., 2008, NOBRE et al., 2011).

Para tanto, o modelo proposto utiliza as informações topográficas de um modelo digital de elevação (MDE) para extrair as informações hidrológicas de uma área (RENNÓ et al., 2008). O MDE é então normalizado, em conjunto com a rede de drenagem fornecida, atribuindo a todos os cursos d'água o nível zero e recalculando a altura das demais células da topografia a partir do corpo hídrico mais próximo (RENNÓ et al., 2008, NOBRE et al., 2011). No presente estudo, o Modelo Digital de Elevação foi produzido a partir da triangulação de pontos cotados na escala 1:1000 a 1:5000, disponibilizados pela prefeitura Municipal de São Paulo, de acordo com metodologia descrita no item 4.2.2.1.

O algoritmo (Figura 5) possibilita então definir alturas que correspondem, não aos seus valores altimétricos absolutos, mas sim aos desníveis do terreno em relação ao rio mais próximo, possibilitando predizer a profundidade do lençol freático a partir da topografia digital (SILVA et al., 2011).

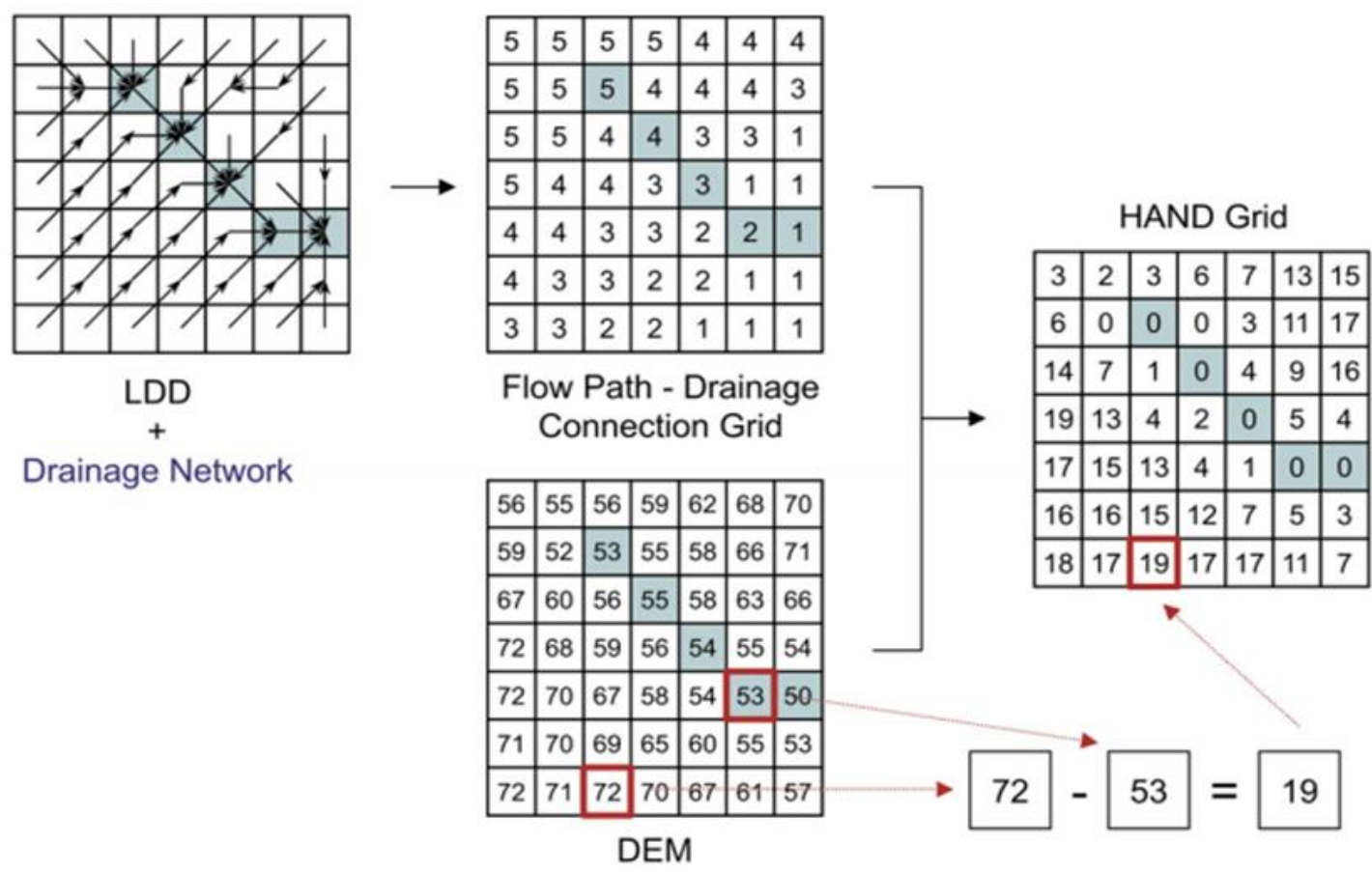

Figura 5 - Procedimento utilizado pelo algoritmo HAND. Fonte: Rennó et al. (2008).

Para tanto, o modelo proposto utiliza as informações topográficas de um modelo digital de elevação (MDE) para extrair as informações hidrológicas de uma área (RENNÓ et al., 2008). O MDE é então normalizado, em conjunto com a rede de drenagem fornecida, atribuindo a todos os cursos d'água o nível 


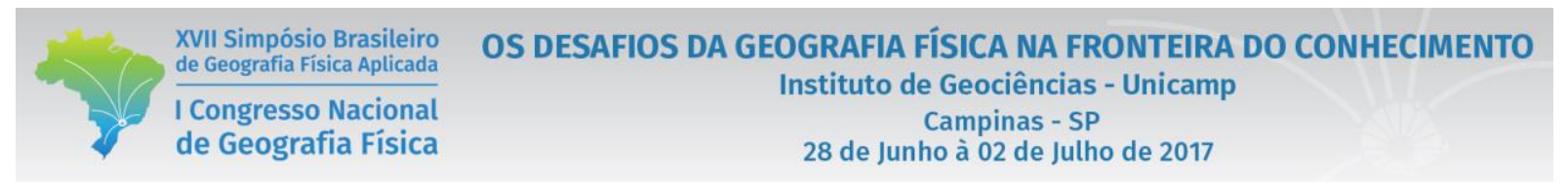

zero e recalculando a altura das demais células da topografia a partir do corpo hídrico mais próximo (RENNÓ et al., 2008, NOBRE et al., 2011). No presente estudo, o Modelo Digital de Elevação foi produzido a partir da triangulação de pontos cotados na escala 1:1000 a 1:5000, disponibilizados pela prefeitura Municipal de São Paulo, de acordo com metodologia descrita no item 4.2.2.1.

Feita a definição do grid, define-se faixas com alturas de elevação do nível da água, obtendo como produto final um mapa com manchas de acúmulo de água correspondentes aos intervalos escolhidos. A etapa de definição das alturas de elevação é de suma importância para que as manchas obtidas sejam condizentes com a realidade que se deseja representar.

\section{Resultados}

No contexto do estudo, considerando as características da topografia da bacia, caracterizada por altas declividades nas porções de cabeceiras e extensas áreas de planície de inundação no baixo e médio curso do rio Aricanduva, foi possível verificar e representar as áreas favoráveis ao acúmulo de água, ou seja, as mais suscetíveis às inundações.

Para tanto, foi escolhida, a partir dos resultados obtidos, a representação referente às alturas de inundação definidas no intervalo de 1-2 metros, onde obteve-se um mapa com a melhor identificação das áreas suscetíveis ao acúmulo de água, de acordo com a figura 6.

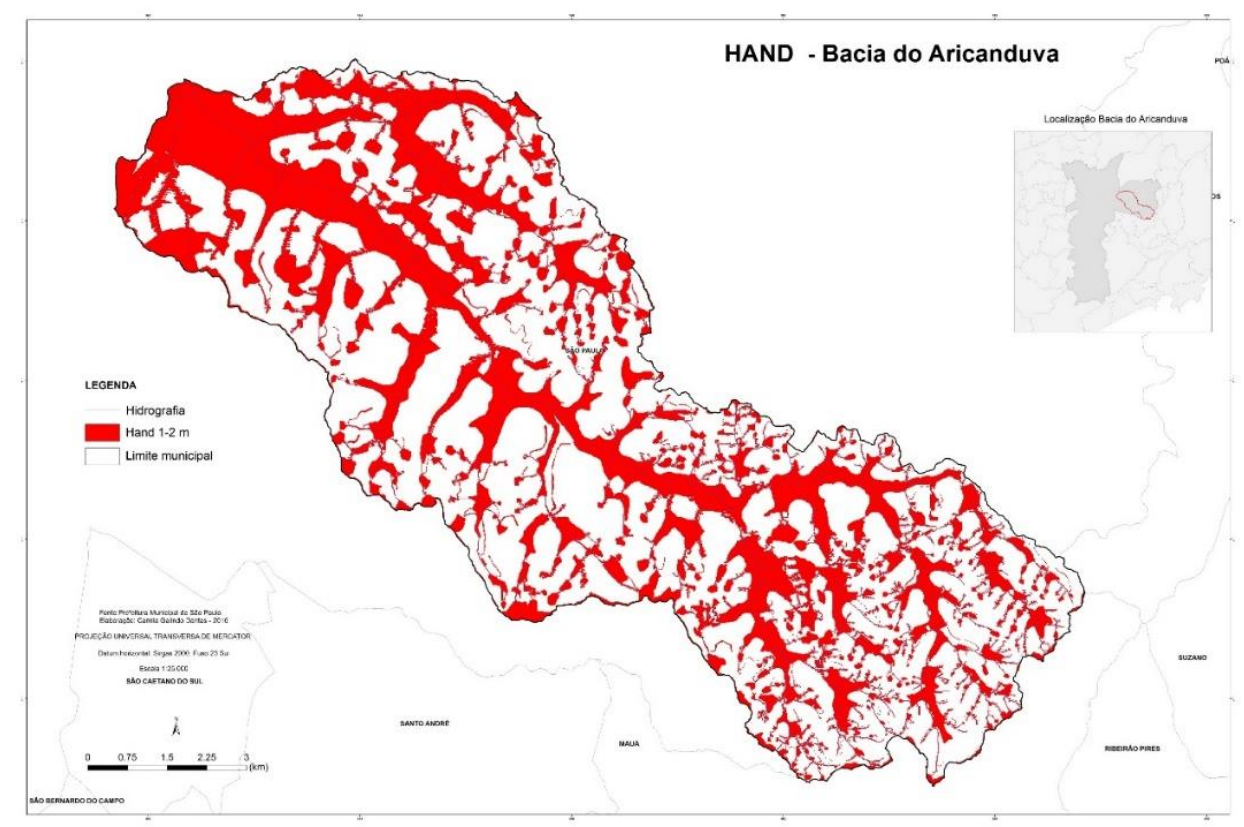

Figura 6: Resultado do modelo HAND na Bacia do Aricanduva. Fonte: Organizado por Camila Galindo Dantas. 


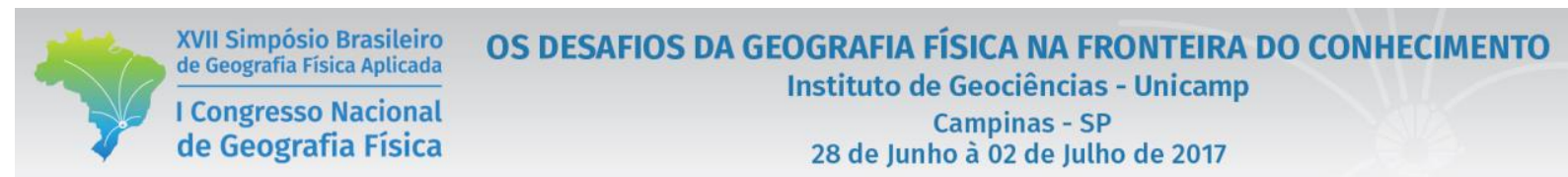

O resultado das zonas indicadas como suscetíveis ao acúmulo de água pelo modelo HAND acompanha os resultados de demais análises desenvolvidas, destacando as áreas de planícies e terraços diferenciadas no mapa geomorfológico (Figura 7). Em paralelo ao resultado do modelo HAND, o levantamento das características do meio físico em conjunto às condições de uso e ocupação do solo apresentadas, indicam a forte suscetibilidade e vulnerabilidade das áreas de planície da bacia do Aricanduva de ocorrer inundações, pois possuem características naturais favoráveis associadas a um quadro antrópico de alta densidade.

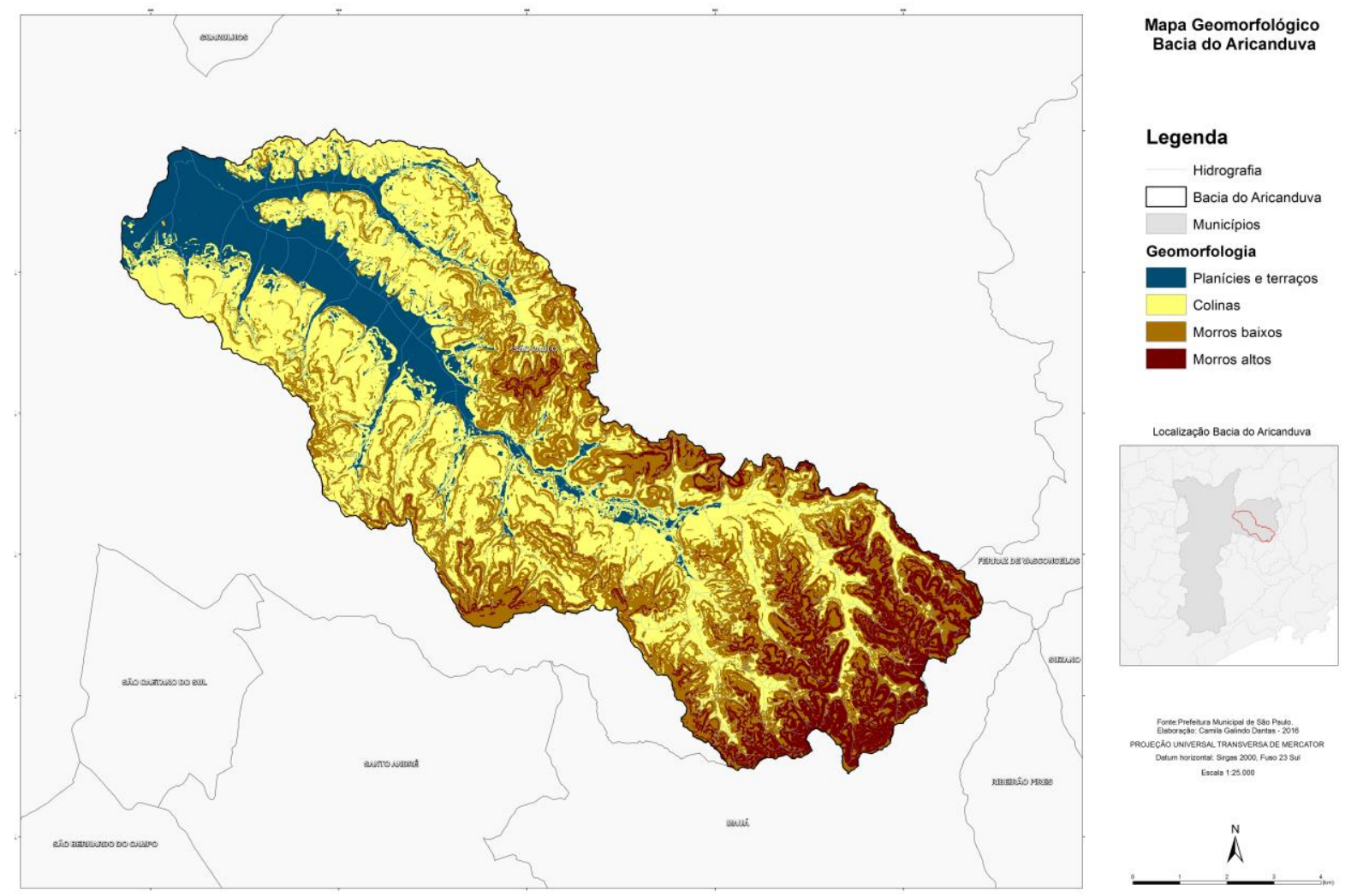

Figura 7: Mapa Geomorfológico da Bacia do Aricanduva. Fonte: Organizado por Camila Galindo Dantas.

Portanto, conclui-se que as áreas mapeadas no intervalo de 1-2 metros pelo modelo HAND, acompanham as regiões com altitudes e declividades mais baixas, além de haver forte correspondência com conhecidos pontos de ocorrência de inundação na bacia do Aricanduva. Dessa forma, o modelo emerge como um resultado que corrobora para aindicação de áreas suscetíveis à ocorrência de inundações e suporte em estudos na temática de mensuração de riscos. 


\section{Bibliografia}

BITAR, O. Y. (coord.). Cartas de suscetibilidade a movimentos gravitacionais de massa e inundações: 1:25.000 (livro eletrônico): nota técnica explicativa. São Paulo: IPT - Instituto de Pesquisas Tecnológicas do Estado de São Paulo; Brasília, DF: CPRM - Serviço Geológico do Brasil, 2014. (Publicação IPT, 2016).

BOTELHO, R. G. M. Bacias hidrográficas urbanas. In: GUERRA, A. (org.). Geomorfologia urbana. Rio de Janeiro: Bertrand Brasil, 2011.

CANHOLI, A. P. Drenagem urbana e controle de cheias. 2. ed. São Paulo: Oficina de Textos, 2014

CARVALHO, C. S.; MACEDO, E. S.; OGURA, A.T. (orgs.). Mapeamento de riscos em encostas e margens de rios. Brasília: Ministério das Cidades; Instituto de Pesquisas Tecnológicas - IPT, 2007.

CUSTÓDIO, W. A persistência das inundações na grande São Paulo. Tese (doutorado), Geografia, FFLCH-USP, São Paulo, 2002.

DEPARTAMENTO DE ÁGUAS E ENERGiA ELÉTRICA (DAEE). Plano diretor de macrodrenagem da bacia hidrográfica do alto Tietê - bacia do Aricanduva. São Paulo, dez. 1999.

KOBYIAMA, M.; MENDONÇA, M.; MORENO, D.A.; MACELINO, I.P.V.O.; MARCELINO, E.V.; GONÇALVES, E.F.; BRAZETTI, L.L.P.; GOERL, R.F.; MOLLERI, G.S.F.; RUDORF, F.M. 2006. Prevenção de Desastres Naturais: Conceitos Básicos. Curitiba: Ed. Organic Trading.

ORGANIZAÇÃO DAS NAÇÕES UNIDAS (ONU). UNISDR - Estratégia Internacional para Redução de Desastres das Nações Unidas. Como Construir Cidades mais resilientes: um guia para gestores públicos. ONU, 2012.

REIS, P. E. O escoamento superficial como condicionante de inundação em Belo Horizonte, MG: estudo de caso da sub-bacia córrego do Leitão, bacia do Ribeirão Arrudas. Dissertação (Mestrado), Geociências, UFMG, Belo Horizonte, 2011.

RENNÓ, C. D. et al. HAND, a new terrain descriptor using SRTM-DEM: mapping terra-firme rainforest environments in Amazonia. Remote Sensing of Environment, 2008.

SILVA, A. S. Solos urbanos. In: GUERRA, A. (org.). Geomorfologia urbana. Rio de Janeiro: Bertrand Brasil, 2011. 